\title{
Introduction: First Nations, Métis, and Inuit in Canada: Understanding the Issues
}

\section{Chapter Objectives}

To explain multiculturalism policy and the nature of Canadian society.

To introduce the three Aboriginal peoples of Canada.

- To explain their demographics and how they compare with the demographics of the Canadian population.

- To survey the significant milestones in governmental response to Aboriginal concerns over the last four decades.

To provide the background to the growth of Aboriginal health as a discrete subject in Canada and to indicate why knowledge of Aboriginal health is important to nurses and other health care providers. 


\section{Key Concepts}

Affordability

Cost of Care

Social Justice

Population Growth

Multiculturalism
Aboriginal Health

Nation

Health Promotion

Population Health

\section{Key Terms}

Romanow Report (Royal

Commission on the

Future of Health Care in

Canada)

Royal Commission on

Aboriginal Peoples

Multiculturalism

Demographics

Ottawa Charter

Status Indian

Non-Status Indian

Treaty Indian
Métis

Inuit

Aboriginal People

Band

Customs

First Nations

Reserve

Treaty

Self-Government

Canadian Charter of Rights and Freedoms 


\section{MULTICULTURALISM}

The Government of Canada declared its commitment to multiculturalism in 1971 and explicitly incorporated multiculturalism into the Charter of Rights and Freedoms when the Constitution was repatriated in 1981. This was partly in response to concerns expressed by Aboriginal groups that the focus on English and French cultures excluded both them and other ethnic groups from equal participation in the Canadian cultural mosaic.

\section{A PART OF THE CANADIAN CULTURAL MOSAIC}

Canada is an immigrant nation, where the original population has been overwhelmed by successive waves of other peoples who have migrated here. Nursing historian John Murray Gibbon recognized that, unlike the "melting pot" model of cultural integration practised in the United States, in Canada different immigrant groups retained substantial elements of their cultural identity, while still participating in Canadian civil society and sharing common values. He called this the Canadian cultural mosaic in his influential book, The Canadian Mosaic, published in 1938. Gibbon explicitly contrasted the mosaic to the American melting pot.

When the Canadian government developed an official multiculturalism policy in 1971, Gibbon was referenced and his concept was used as the model for intercultural relations in Canada. This provided an alternative model of Canadian society to both assimilation and English-French biculturalism. Over time the concept has evolved, but multiculturalism and the cultural mosaic is still the basis for Canadian concepts of their national social organization. This was affirmed by Section 27 of the Charter of Rights and Freedoms and was enshrined in law in the Canadian Multiculturalism Act in 1985.

\section{Multiculturalism Policy of Canada}

3. (1) It is hereby declared to be the policy of the Government of Canada to

(a) recognize and promote the understanding that multiculturalism reflects the cultural and racial diversity of Canadian society and acknowledges the freedom of all members of Canadian society to preserve, enhance, and share their cultural heritage;

(b) recognize and promote the understanding that multiculturalism is a fundamental characteristic of the Canadian heritage and identity and that it provides an invaluable resource in the shaping of Canada's future;

(c) promote the full and equitable participation of individuals and communities of all origins in the continuing evolution 


\section{Multiculturalism Policy of Canada (continued)}

and shaping of all aspects of Canadian society and assist them in the elimination of any barrier to that participation;

(d) recognize the existence of communities whose members share a common origin and their historic contribution to Canadian society, and enhance their development;

(e) ensure that all individuals receive equal treatment and equal protection under the law, while respecting and valuing their diversity;

(f) encourage and assist the social, cultural, economic, and political institutions of Canada to be both respectful and inclusive of Canada's multicultural character;

(g) promote the understanding and creativity that arise from the interaction between individuals and communities of different origins;

(h) foster the recognition and appreciation of the diverse cultures of Canadian society and promote the reflection and the evolving expressions of those cultures;

(i) preserve and enhance the use of languages other than English and French, while strengthening the status and use of the official languages of Canada; and

(j) advance multiculturalism throughout Canada in harmony with the national commitment to the official languages of Canada.

(2) It is further declared to be the policy of the Government of Canada that all federal institutions shall

(a) ensure that Canadians of all origins have an equal opportunity to obtain employment and advancement in those institutions;

(b) promote policies, programs, and practices that enhance the ability of individuals and communities of all origins to contribute to the continuing evolution of Canada;

(c) promote policies, programs, and practices that enhance the understanding of and respect for the diversity of the members of Canadian society;

(d) collect statistical data in order to enable the development of policies, programs, and practices that are sensitive and responsive to the multicultural reality of Canada;

(e) make use, as appropriate, of the language skills and cultural understanding of individuals of all origins; and

( $f$ ) generally, carry on their activities in a manner that is sensitive and responsive to the multicultural reality of Canada.

(Canadian Multiculturalism Act, 1985) 


\section{Section 27 of the Canadian Charter of Rights and Freedoms Is Somewhat Less Verbose. It States:}

This Charter shall be interpreted in a manner consistent with the preservation and enhancement of the multicultural heritage of Canadians.

(Charter of Rights and Freedoms, 1982)

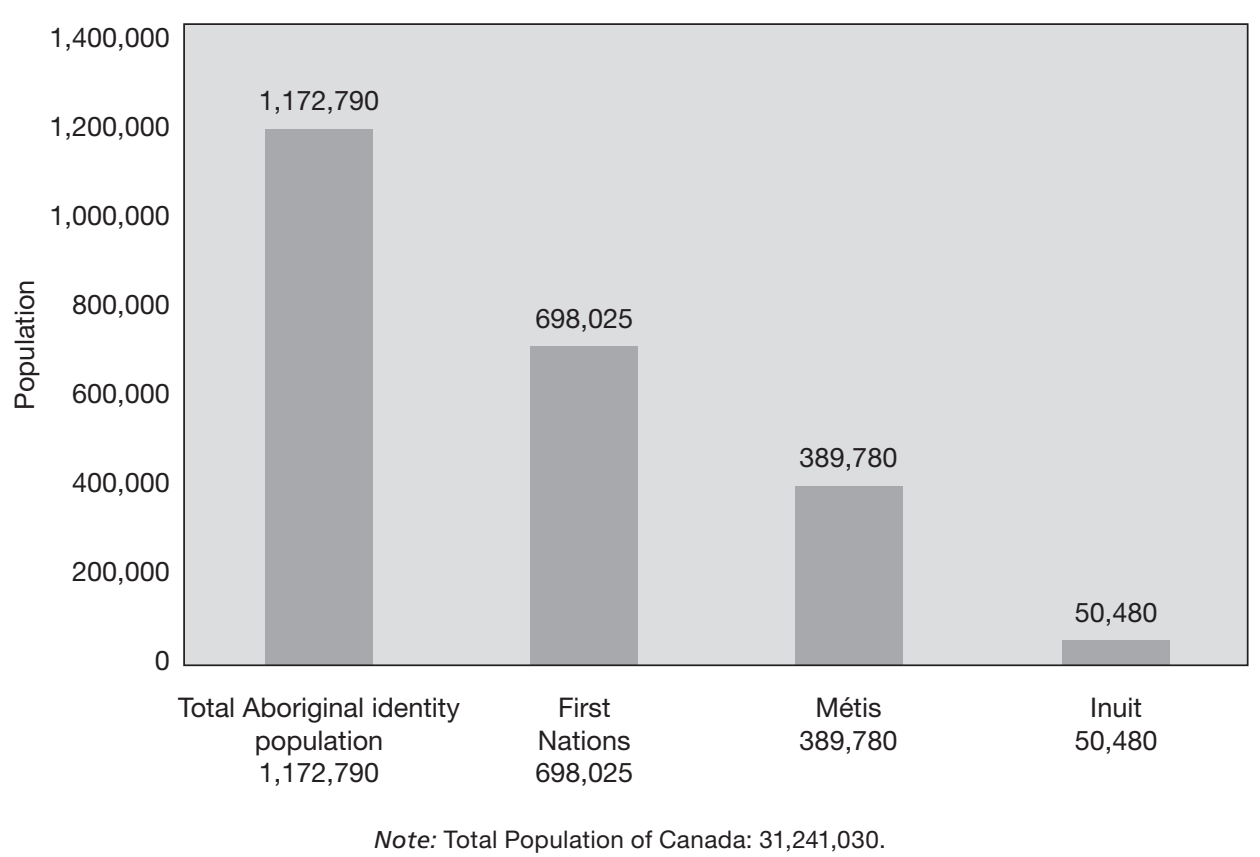

Figure 1.1 Aboriginal Demographics According to Statistics Canada 2006 Source: Statistics Canada, Census of Population, 2006.

\section{A FOUNDING NATION OF CANADA}

Beyond the place Aboriginal peoples hold in Canada's cultural mosaic, they have been recognized, along with the English and French, as one of Canada's three founding nations. Although Canada recognizes the place of all ethnic groups in the cultural mosaic, these three groups are considered founders of the nation due to their roles in the creation of Canada. The First Nations, Métis, and Inuit are recognized as having a special place because they were here first, and they played a key role in the creation of Canada.

\section{DEMOGRAPHICS OF CANADA'S NATIVE POPULATION}

Canada's Aboriginal population is diverse and widespread (Figure 1.1). Although many Aboriginal peoples share common cultural characteristics, many do not. In addition, government policy has created divisions within the Aboriginal 


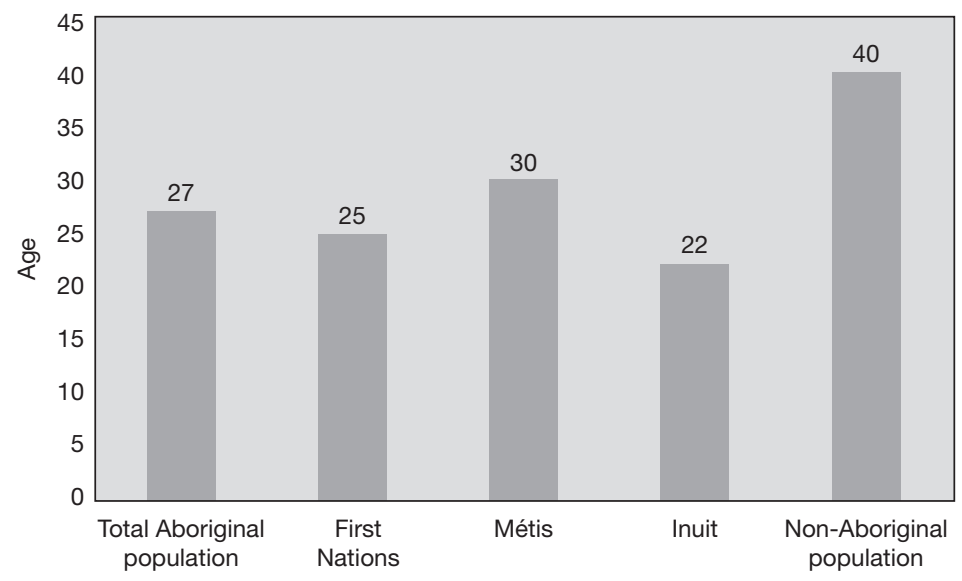

Figure 1.2 Median Age of the Aboriginal and Non-Aboriginal Population

Source: Statistics Canada, Census of Population, 2006.

population, some reflecting existing cultural and social divides, others redefining groups on the basis of their eligibility for government programs. Overall Canadian Aboriginal populations are younger than the general population (a median age of 20 vs. 40 for the general population) (Figure 1.2) and less well educated.

\section{FIRST NATIONS}

The Canadian First Nations are the Aboriginal peoples who reside below the Arctic Circle and who are part of a continuum of Aboriginal peoples who, despite enormous social, linguistic, and cultural diversity, stretch from boreal Canada to South America. In Canada, they are divided into two groups, Status Indians and Non-Status Indians.

\section{Status Indians}

Status Indians are those First Nations who are officially recognized by the Department of Aboriginal Affairs as legally members of an existing First Nations band. There are approximately 565,000 Status Indians in Canada, making them the largest Aboriginal group by population (see Figure 1.1). Their communities and reserves stretch from coast to coast, and many also live in urban areas as well.

Status means eligibility for certain government programs, some of which might be specific to the treaty rights of that band. Each Status Indian receives a band number and identity card to provide access to services. Indian Status provides some privileges, including income tax exemption, but only for Status Indians residing on their reserves. Status Indians living and working off reserve have much the same rights and responsibilities as any other Canadian.

Eligibility for Indian status is determined through ancestry, but not through blood. It is gained through inheritance of status itself. The children of Status 
Indians and Non-Status individuals are eligible for registration, but they must marry someone else with status for their children to inherit it. If they marry someone without status, whether a Non-Status Indian or a non-Indian, then their children lose status. Since the majority of Status Indians form relationships with non-status partners, this provision has serious implications for the long-term viability of Indian Status in Canada.

Historically, Indian Status brought far more restrictions than privileges. Status Indians were required to live on their reserves, were subject to movement controls in some regions (particularly the Prairies), were barred from voting, were not allowed to drink alcohol, and were closely supervised by Indian Agents resident on their reserves. In effect, Status Indians were wards of the state, with a status similar to that of children. These restrictions could only be evaded by an individual giving up status, leaving the reserve, and entering the general population: effectively ceasing to be Aboriginal. While some Aboriginal individuals were willing to do this, most were not. Those who gave up their status, and their descendants, either merged into the general population, or became Non-Status Indians.

\section{Non-Status Indians}

Non-Status Indians number approximately 130,000 (see Figure 1.1). They are people of Aboriginal ancestry who self-identify as First Nations, but cannot claim status for various reasons. These reasons may include their ancestors voluntarily giving up their status, female ancestors losing their status by marrying a non-First Nations man, or other equivocal factors (such as the lack of documentation). These leave Non-Status Indians either unable or unwilling to qualify for Indian Status. Non-Status Indians are not eligible for government programs or services provided to Status Indians and, therefore, do not have the right to reside on First Nations reserves.

However, government recognition has no bearing on their participation in Aboriginal culture and society. Non-Status Indians may be as intimately involved in the culture of their community as Status Indians, even if Canadian governments do not recognize this fact. The existence of status and the right of Canadian governments to decide who, in effect, is Aboriginal and who is not is a very contentious one. Recently, Canadian governments, at the federal, provincial, and municipal levels, have extended various cultural services to Non-Status Indians, without actually granting them Status or access to federal services for Status Indians. Concomitantly, this is now the fastest growing Aboriginal group in Canada as people of First Nations ancestry are publicly reclaiming their heritage and identity, even without the benefits of status.

\section{INUIT}

The Inuit are a separate, non-First Nation indigenous people inhabiting Canada's high Arctic. They are closely related to other indigenous peoples in the circumpolar north, including those of Greenland, Alaska, and the Russian Arctic. According to the 2006 Census, the Inuit population of Canada is approximately 


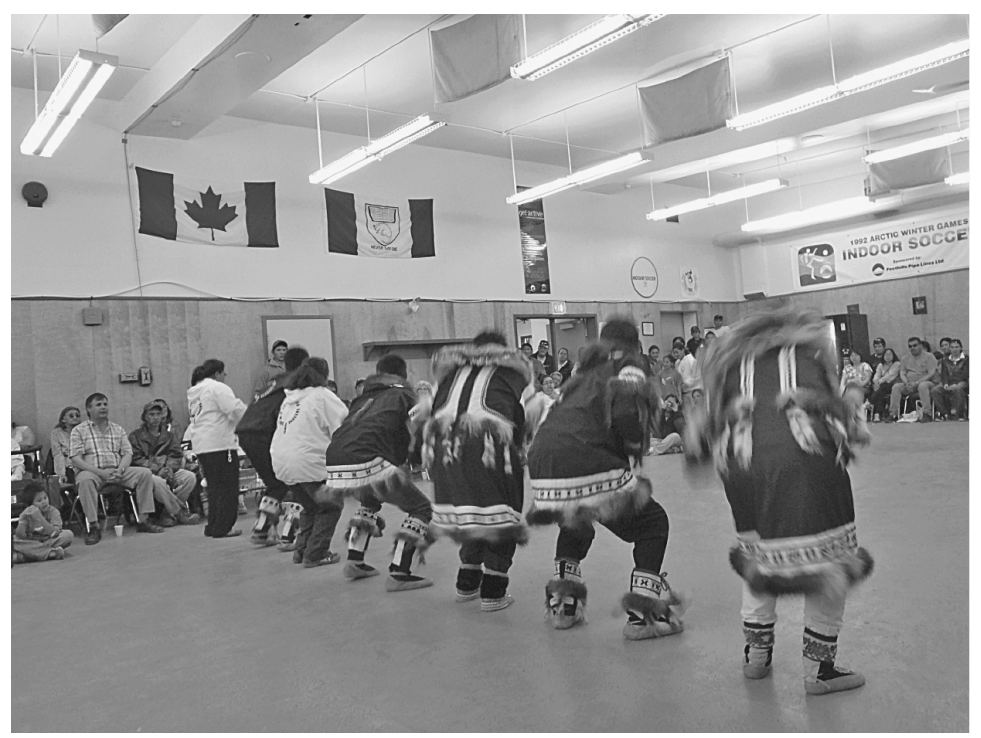

Traditional Dance in an Arctic Community

Source: V. K. Douglas.

50,000 in number (see Figure 1.1). The Inuit comprise the majority of the population in Canada's newest territory, Nunavut, and have a substantial presence in the Northwest Territories, Northern Québec, and Northern Labrador, the region they refer to as Inuit Nunangat.

\section{MÉTIS}

Canada's Métis population is close to 400,000 (see Figure 1.1). The Métis are the descendants of marriages between Aboriginal women and fur traders and explorers. Traditionally, the origin of the Métis is the Red River Settlement of the Hudson's Bay Company and it was also the largest Métis settlement. However, Métis settlements spread across Canada, springing up wherever a fur trading post was established along the trading routes. A hybrid culture, the Métis evolved from their mixed ancestry into a unique indig-

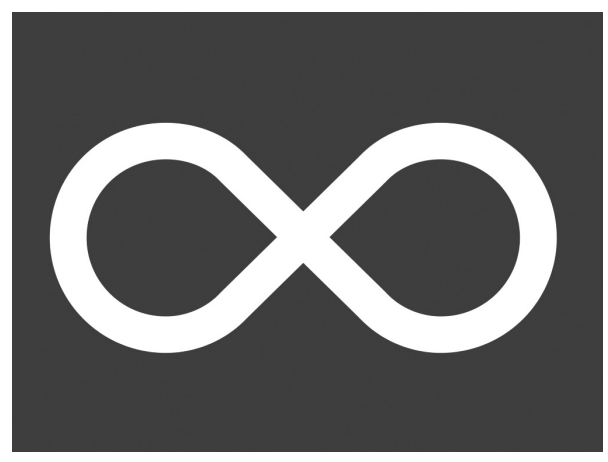

The Métis Flag enous people, neither First Nations nor European, but combining aspects of each into a separate whole. The Métis were recognized as a separate people by both of the fur trading companies active in the Northwest Territories, the Northwest Company, and the Hudson's Bay Company. When Western Canada was incorporated into the Confederation in 1867, the Canadian government was also forced to 
recognize the existence of the Métis as a distinct people. Despite dispersal across the west after the Red River and Northwest Rebellions in 1869 and 1885, and a subsequent history of marginalization, the Métis have survived and now claim a place among Canada's other indigenous peoples.

The Métis flag in predates all other contemporary Canadian flags except for the Royal Ensign. The Métis flag was flown by the Métis as early as 1816, although the infinity symbol can also be set upon a red background. The flag symbolizes the union of two people and the belief that the Métis culture shall live forever.

\section{URBAN ABORIGINALS}

This is not a formal grouping, but a geographic one. The increasing urbanization of Canada following the Second World War has also affected the Aboriginal population. Thus, Canadian cities host substantial Aboriginal populations that have migrated there in search of employment, education, and socioeconomic opportunities. Often these peoples moved to urban centres at government urging in the 1960s and 1970s, with the belief that there would be better services and employment opportunities than in the remote communities they came from. On the government's part, this was both an attempt to improve the economic situation of remote, impoverished citizens, and part of the ongoing program of assimilation of Aboriginal peoples by encouraging them to blend into existing urban populations.

This population movement blends groups from widely differing geographic and cultural regions, leading to significant migration of cultural practices. For instance, the Medicine Wheel, a traditional Prairie First Nations concept of health, is now used in urban Aboriginal populations in British Columbia, even though it is not traditionally used by the indigenous First Nations population there. Urban Aboriginal populations may include Status Indians, Non-Status Indians, Métis, and some Inuit. Health status varies widely among individuals across the urban Aboriginal population, but their experiences are characterized by high levels of poverty and poor access to health care despite their proximity to urban health care facilities and services.

\section{ABORGINAL PEOPLES IN CANADA}

The Canadian Aboriginal population (Figure 1.3) is substantial and growing rapidly, especially the Non-Status Indian and Métis populations, which are benefiting from increased willingness of people of Aboriginal ancestry to self-identify as Aboriginal. However, even smaller populations may be regionally significant. The Inuit form a majority in Nunavut, whereas western and northern Canada have significant Aboriginal populations, often regional majorities. Thus, the Northwest Territories have a majority Aboriginal population (combined First Nations and Inuit), as does Nunavut, and Northern Québec and Northern Labrador. 


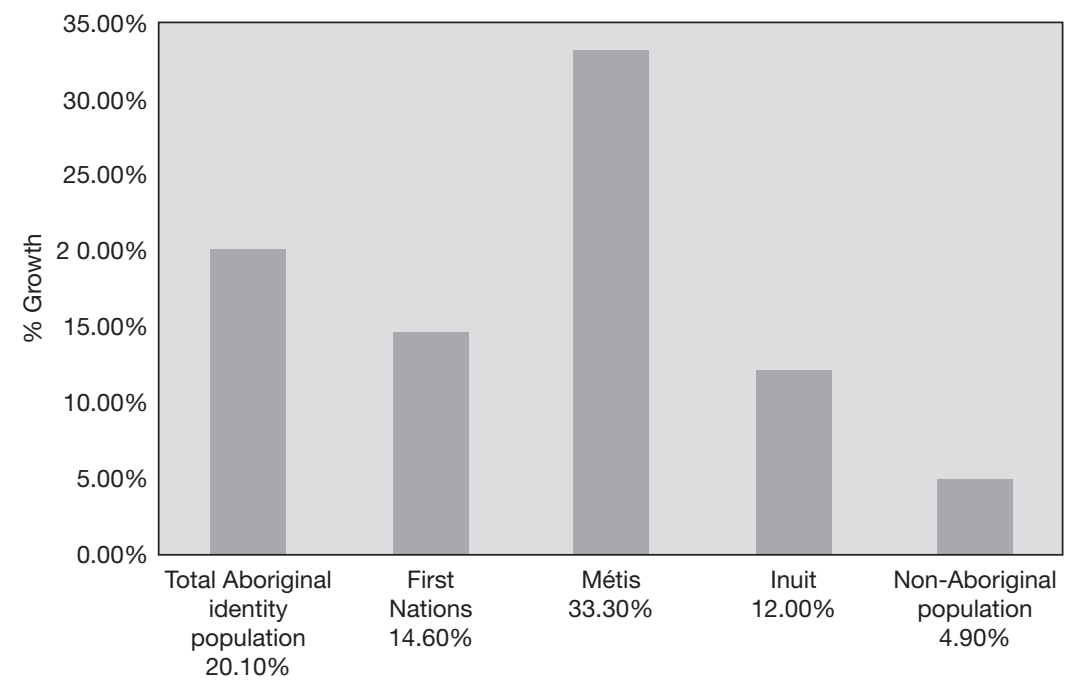

Figure 1.3 Growth of the Aboriginal Population, 2001-2006

Source: Statistics Canada, Census of Population, 2006.

Not only is the Aboriginal population growing much faster than the general population, but their family characteristics also differ. A high proportion of Aboriginal children live in single-parent families, yet also paradoxically benefit from active large multigenerational families. However, these families typically reside in more crowded, less prosperous conditions than families in the general population. Other socioeconomic indicators are also lower: Unemployment rates are high in the Aboriginal population, while high school and postsecondary education rates are lower than those of the general population.

\section{OTTAWA CHARTER}

The World Health Organization (WHO) held the first International Conference on Health Promotion in 1986. Although not specifically concerned with Aboriginal health, the conference marked a significant shift in focus for public health policy from prevention of disease to identifying and improving the determinants of health. The conference concluded with the Ottawa Charter on Health Promotion (1986), which identified the social and environmental prerequisites of health as: peace, shelter, education, food, income, a stable ecosystem, sustainable resources, social justice, and equity. In essence, the Ottawa Charter recognized that health is a byproduct of a healthy environment. In pursuit of this goal, the Charter envisaged a variety of actors, including government, nurses, physicians and other public and private bodies, cooperating to improve all of these factors as a means of improving the health of the entire population.

The Ottawa Charter was officially adopted by the WHO after the conference. Its prerequisites for health have evolved into the modern basis for public 
health in Canada-the determinants of health. This approach has informed the Canadian approach to public health ever since, and indeed forms the basis for attempts to improve the health of Canada's Aboriginal peoples. The Charter's principles recognize that as long as one segment of the Canadian population remains in ill health, the health of the entire population will inevitably suffer. The Ottawa Charter did not lead to any immediate changes in the structure of health care and health promotion in Canada. However, it recognized that the focus should change from reacting to specific health crises, such as outbreaks of infectious disease, to promoting the health of the general population before it could become endangered.

\section{ROYAL COMMISSION ON ABORIGINAL PEOPLES AND THE ROMANOW REPORT}

The Royal Commission on Aboriginal Peoples was founded in the wake of the Oka Crisis, when public and international awareness of the poor socioeconomic conditions that Canada's Aboriginal peoples laboured under was at its height. Its Commissioners included some of the most eminent Aboriginal scholars and politicians in Canada. The Commission produced a lengthy report in 1996 that made some key recommendations.

The Report suggested that Parliament pass legislation, including a Royal Proclamation, committing Canada to a new relationship with its Aboriginal peoples. As well, the Commission recommended that Canada create a national Aboriginal parliament, create legislation to initiate a new treaty process and also recognize Aboriginal nations and governments as integral parts of the Canadian order of government. The Commission also called for the Department of Indian and Northern Affairs to be abolished and replaced with two departments, one dealing with self-governing Aboriginal groups, the other dealing with non-self-governing groups. The Commissioners also recommended that the Aboriginal land and resource base be expanded and that Métis be granted self-government and full Aboriginal rights (equal to Indian status). Finally, the Commission recommended that 10,000 health professionals be trained to improve Aboriginal health and that Aboriginal authority over education and child welfare be recognized.

Coincidentally, the Commission's report arrived when a new government had taken power, one primarily concerned with reducing the Federal budget deficit through stringent spending controls. Thus, most of the Commission's recommendations were ignored, although its recommendations did lead to the gradual devolution of powers from the Department of Indian and Northern Affairs to local Aboriginal authorities.

This development served two purposes, however, as it placed the responsibility for health on First Nations themselves, which handily removed direct federal responsibility for health outcomes. The devolution of powers also satisfied some of the demands of Aboriginal activists for greater control of their own affairs. 
Much more tellingly, other more far-reaching proposals of the Commission were not implemented. Aboriginal self-government was an inexpensive, cost-saving measure, which resonated with the government of the day.

\section{Text From the Preamble of the Royal Commission on Aboriginal Peoples}

Canada is a test case for a grand notion-the notion that dissimilar peoples can share lands, resources, power and dreams while respecting and sustaining their differences. The story of Canada is the story of many such peoples, trying and failing and trying again, to live together in peace and harmony.

\section{The Oka Crisis}

The Oka Crisis erupted in 1990 and led to a tense stand-off between the Canadian army and armed Mohawk activists on the Kanesatake reserve near the village of Oka, Québec. The crisis originated in a land dispute. The village of Oka planned to expand its municipal golf course onto a plot of land that was claimed by the Mohawk as a traditional burying ground. The intransigence of the municipal government led to rapid escalation and the involvement of the provincial police, the Surété du Québec. After a police officer was shot and killed during an ill-advised attempt to rush a Mohawk road blockade, the Québec government requested assistance from the Federal Government under the National Defence Act and sent in the Canadian Army. The result was to galvanize Aboriginal activists across Canada. Protests took place and road blockages were erected in support of the Mohawk across the country, most notably in Québec, where the major freeway bridge across the Saint Lawrence River was blocked by Mohawks from the Kahnawake reserve, effectively cutting off the city of Montréal from its suburbs on the South Shore.

Fortunately there were no further fatalities, and after a prolonged siege the activists surrendered in return for some consideration of their grievances. Oka, however, has left two legacies. First, it actually increased Canadian public awareness and sympathy for the plight of Canadian Aboriginal peoples, and second, it exposed to international gaze the poor socioeconomic conditions many Aboriginals laboured under. The Federal Government was highly embarrassed, as it had 


\section{The Oka Crisis (continued)}

previously shown impressive leadership on international issues such as apartheid in South Africa, only to be accused of more covert racism toward its own Aboriginal population at home. The Oka Crisis also increased Aboriginal militancy, as the violence at Oka seemed to work better than the quiet diplomacy pursued by advocacy groups such as the Assembly of First Nations. The Oka Crisis was soon to be succeeded by armed confrontations at Gustafsen Lake in British Columbia, Ipperwash Provincial Park in Ontario, and Burnt Church in New Brunswick.

Indirectly, the threat of further confrontations may have encouraged both provincial and federal governments into greater attempts to resolve Aboriginal issues. Following these conflicts the federal government created the Royal Commission on Aboriginal Peoples, while the British Columbia provincial government finally began the process of dealing with its own long-standing land claims issues after over a century of colonization and denial.

\section{Romanow Report}

While the Royal Commission on Aboriginal Peoples saw much of its report relegated to the archives in 1996, by the end of the century health care had become an urgent issue in Canada and led to the creation of the Royal Commission on the Future of Health Care in Canada, led by the former Premier of Saskatchewan, Roy Romanow. The Romanow Report was released in 2002 and, like its predecessor, found serious shortcomings in the health experience of Canada's Aboriginal peoples. In the Report's words:

In fundamental terms, there is a "disconnect" between Aboriginal peoples and the rest of Canadian society, particularly when it comes to sharing many of the benefits of Canada's health care system. There are at least five underlying reasons for this disconnect:

- Competing constitutional assumptions

- Fragmented funding for health services

Inadequate access to health care services

- Poorer health outcomes

- Different cultural and political influences

(Romanow Report, 2002, p. 212. Permission granted by the Privy Council Office $@$ Her Majesty the Queen in Right of Canada, 2017).

Unlike its predecessor, the Romanow Report concluded that adequate funds were available to improve Aboriginal health care, but most of them were wasted 
in mismanagement and in the fragmentation of resources. Romanow's recommendations were to:

- Consolidate fragmented funding for Aboriginal health to take the best advantage of the total potential funds available in order to improve health and health care for Aboriginal peoples;

- Create new models to co-ordinate and deliver health care services and ensure that Aboriginal health care needs are addressed;

- Adapt health programs and services to the cultural, social, economic, and political circumstances unique to different Aboriginal groups; and

Give Aboriginal peoples a direct voice in how health care services are designed and delivered.

(Romanow Report, 2002, p. 212. Permission granted by the Privy Council Office@ Her Majesty the Queen in Right of Canada, 2017).

While not all of the Romanow Report's recommendations have been followed to date, some action has been taken, including the creation of an Aboriginal health authority, the First Nations Health Authority, in British Columbia in 2011. There are also ongoing attempts to adapt and create health programs that are tailored to the needs of Aboriginal communities.

\section{EASING DEMANDS ON RESOURCES}

Perhaps more importantly, Romanow identified serious systemic problems with the Canadian health care system in general. He found that, despite the recommendations of the Ottawa Charter, the system still focused its resources on the treatment and prevention of disease and ill health. He recommended that a serious focus on the determinants of health would be more effective and economical in maintaining the health of the general population. The dual focus on saving money and improving service delivery has made Romanow's recommendations more attractive to economy-minded Canadian governments than the far-reaching conclusions of the Royal Commission. In those cases where he recommended increased expenditures (such as pharmaceutical expenses), his report has proved less influential and thus, little has changed.

However, because Romanow's recommendations focused at the level of population health, they also apply to the Aboriginal population. The result has been some improvements in health care delivery and on developing programs focused on population health among the Aboriginal community as part of the overall change in focus stemming from the Report.

The Romanow Report clearly laid out the advantages to improving the determinants of health for the Aboriginal population. Its conclusions can be simplified as in Figure 1.4.

The Canadian Aboriginal population has a high birth rate and is growing rapidly. The general population is not, although immigration is continuing to 
contribute to overall population growth. Health issues in the Aboriginal population have serious implications for Canadian economic, social, and physical wellbeing, given these trends. If a large proportion of the population lives in poverty and misery, it will drag the rest of the population down, through cost to the health care system, contagion, and social problems.

Regional statistics are also only part of the story. Within each province are regions that have much larger Aboriginal populations than the provincial totals indicate. The northern regions of both Ontario and Québec comprise over half of their total geographic area, and the Aboriginal populations of both provinces are concentrated in these regions, while the non-Aboriginal population is concentrated in the south (Figure 1.5).

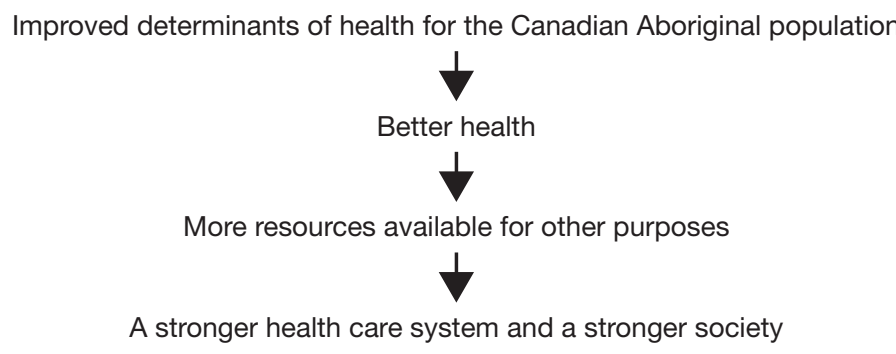

Figure 1.4 Summarizing the Main Conclusions of the Romanow Report Source: V. K. Douglas.

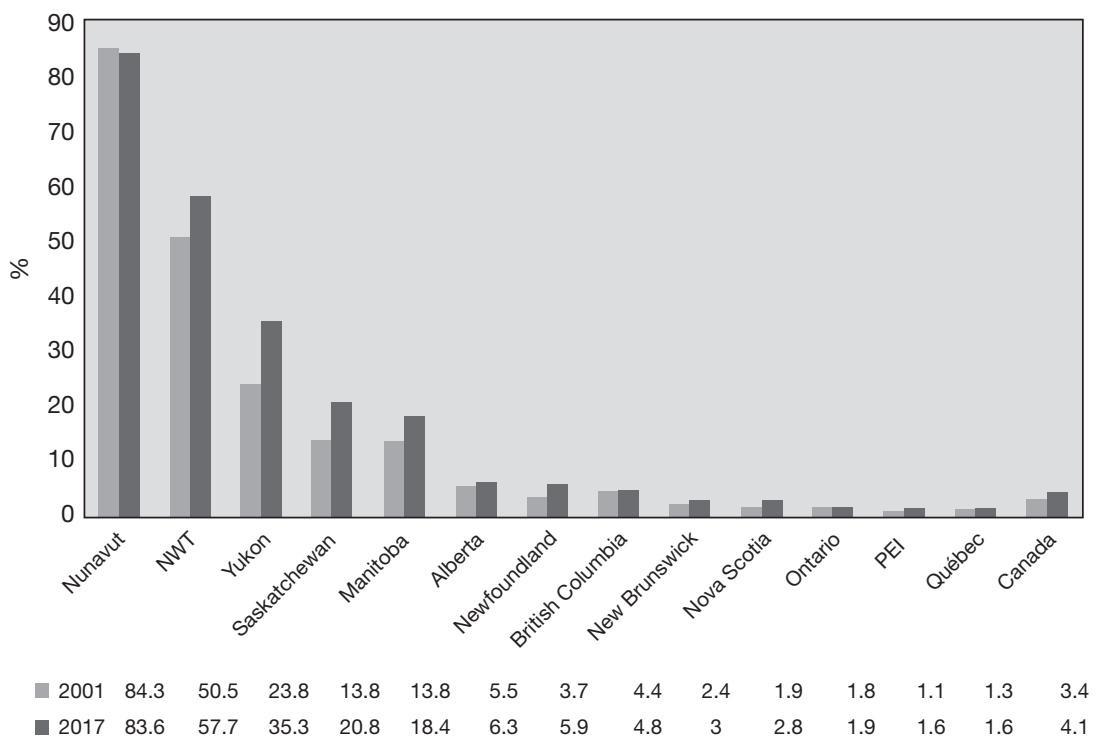

Figure 1.5 Aboriginal Population Trends to 2017

Proportion of the Aboriginal population in the total population by province andterritory, 2001 and 2017 (projected) Source: Statistics Canada 2005. 


\section{CRITICAL THINKING EXERCISE-THINKING ABOUT DIFFERENCE}

Valuing and identifying cultural differences exercises are common. This is a hybrid of several exercises designed to help bring to light one's membership in the dominant cultural group in Canada.

This exercise can be performed alone, but is better when done as a group exercise, comparing your results with others' results.

First ask yourself this series of questions. Give yourself one point for "Yes" and subtract one point for "No."

1. You are female.

2. You are under 25 years of age.

3. You have brown eyes.

4. You are of non-Caucasian ancestry.

5. You have ever been afraid to walk in your neighborhood at night.

6. You attend church or temple regularly (not necessarily every week).

7. You have ever participated in a sweat.

8. You have used herbs for health purposes.

9. You have gone to elementary or high school away from your family.

10. You have not been allowed to speak your language of birth.

11. You have been followed by security personnel while shopping in a store.

12. You have been refused any service due to your age, ethnicity, or gender.

13. You know of community services for Aboriginal peoples.

14. You have cultural practices other families you know may not.

15. You understand the socioeconomic factors that influence Aboriginal health.

Add up your results. A high score indicates you are marginalized. A low or negative score indicates the degree you are a member of the dominant group in Canadian society. Which group do you think this is? 


\section{Discussion Questions}

1. Why were the recommendations of the Royal Commission on Aboriginal Peoples largely ignored?

2. The Federal Government did devolve power to Aboriginal governments in the 1990s and after. What are two interpretations of why this happened?

3. Who has the largest population among the Aboriginal peoples of Canada?

4. What was the impact of the Oka Crisis on Canadian governments?

5. What was the impact of the Oka Crisis on Aboriginal activism?

6. What is the fastest growing group among the Aboriginal peoples of Canada? Why?

7. What does the Métis flag symbolize?

8. Why is Aboriginal population growth significant for even overwhelmingly non-Aboriginal provinces, such as Ontario or British Columbia?

\section{REFERENCES AND FURTHER READING}

An Act for the preservation and enhancement of multiculturalism in Canada (Canadian Multiculturalism Act). R.S.C., 1985, c. 24 (4th Supp.).

Canadian Charter of Rights and Freedoms, s 2, Part I of the Constitution Act, 1982, being Schedule B to the Canada Act 1982 (UK), 1982, c 11.

Esses, V. M., \& Gardner, R. C. (1996). Multiculturalism in Canada: context and current status. Canadian Journal of Behavioural Science/Revue canadienne des sciences du comportement, 28(3), 145.

Frideres, R. (2008). Aboriginal identity in the Canadian context. Canadian Journal of Native Studies, XXVIII(2), 313-342.

Gibbon, J. (1938). The Canadian mosaic: the making of a northern nation. Toronto, ON: McClelland \& Stewart.

Kymlicka, W. (2003). Canadian multiculturalism in historical and comparative perspective: is Canada unique. Constitutional Forum, 13, 1-8.

Légaré, E. I. (1995). Canadian multiculturalism and Aboriginal people: Negotiating a place in the nation. Identities: Global Studies in Culture and Power, 1(4), 347-366.

Porter, J. (1965). The vertical mosaic: An analysis of social class and power in Canada. Toronto, ON: University of Toronto Press. 
Statistics Canada. (2005). Projections of the Aboriginal populations, Canada, provinces and territories (2001 to 2017). Ottawa, ON: Statistics Canada.

Woodcock, G. (1990). A social history of Canada. Toronto, ON: Penguin Books.

\section{Recommended Websites}

First Nations Health Authority: www.fnhc.ca/index.php/iFNHA/

Ottawa Charter Emblem: www.who.int/healthpromotion/conferences/previous/ottawa/ en/index4.html

Ottawa Charter on Health Promotion: www.who.int/healthpromotion/conferences/previous/ottawa/en/index.html

Report of the Royal Commission on Aboriginal Peoples: www.parl.gc.ca/Content/LOP/ ResearchPublications/prb9924-e.htm

Report of the Royal Commission on the Future of Health Care in Canada (Romanow Report). http://publications.gc.ca/site/eng/237274/publication.html 